\title{
Alçı Sıkılama Yöntemi için Arazide Uygulama Kolaylığının Araştırılması
}

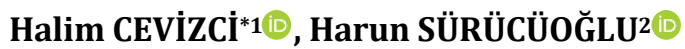 \\ ${ }^{1}$ Süleyman Demirel Üniversitesi, Mühendislik Fakültesi, Maden Mühendisliği Bölümü, 32100, Isparta, Türkiye \\ ${ }^{2}$ Defne OSGB, Karaman Mh. Fatih Cd. No:148, Denizli, Türkiye
}

(Alınıș / Received: 13.01.2020, Kabul / Accepted: 18.01.2021, Online Yayınlanma / Published Online: 15.04.2021)

Anahtar Kelimeler
Alçı sıkılama,
Sıkllama,
Uygulama kolaylığı,
Fragmentasyon,
Wipfrag,
Maliyet

Anahtar Kelimeler

Alçı sıkılama,

Uygulama kolaylığı,

Wipfrag,

Maliyet

. 


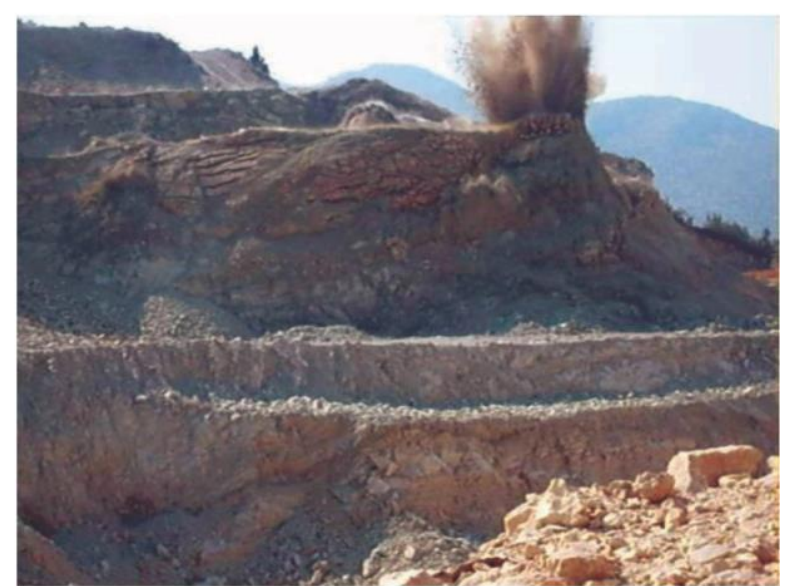

Şekil 1. Taş tozu sıkılamada sıkılama malzemesinin fışkırması [5].

Alçı sıkılama, delme patlatma maliyetlerinde \%20-30 kar sağlayabilmektedir [6]. Hem de daha iyi parçalanma sağlamıştır. Ne var ki, yeni bir uygulama için, teknik ve bilimsel verilerin yanında, firma sahibi ve uygulayıcılar için uygulamanın iyi bilinmesi, ergonomi ve psikolojik faktörler de önemlidir [7].

Alçı sıkılaması deyiminden; su içine katılan alçının koyu ayran kıvamında hazırlanması ile elde edilen bulamacın, deliklere doldurularak, sertleşmesi yoluyla yapılan sıkılama ifade edilmektedir [8].

Sıkılamanın alçı ile yapılmasının kârlılığı çok sayıda bilimsel çalışmada, açıkça ortaya konmuştur. Ancak alçının elle hazırlanması ve birçok deliğe ayrı ayrı dökülmesi çok vakit alacağından bu sürecin bir makine yardımıla gerçekleștirilmesi amaçlanmaktadır. Makine ile yapılan alçı sıkılama sayesinde zaman ve zahmet azalacaktır. $\mathrm{Bu}$ gelişmelerin zamanla adım adım ilerlemesi beklenmektedir.

\section{Materyal ve Metot}

Çalışmalar, halen faaliyette bulunan bir kireçtaşı ocağında gerçekleştirilmiştir [9]. Alçı ve taş tozu sıkılamalı atımda temel patlatma parametreleri Tablo 1 'de belirtilmiştir.

Çalışmada, arazi uygulamaları için önceki çalışmalardaki en büyük sorunlardan biri, alçı su karıştırılması idi. Bu amaçla, araç aküsünden enerji alarak $220 \mathrm{~V}$ olarak çıkış sağlayan bir inverter ve şarjlı matkaplar kullanılmıştır.

\subsection{Dinar Ocağı Uygulamaları}

Daha önce patlatma yapılan kademelerde hafriyat çalışmaları devam etmekte olup, patlatma yapılacak olan bölge en üst kademeyi teşkil etmektedir. Dolayısı ile de bâkir arazi şartlarında patlatma gerçekleştirilmiştir. Önceden alınmış dilimler ile düzgün serbest ayna yüzeyine doğru atım gerçekleştirildi. Ancak, hem alçı hem taş tozu sıkılamalı atımda, yataya yakın bir bakir arazi yüzeyinde delikler delinmiş ve patlatma gerçekleștirilmiştir.

Patlatma bölgesine taşınması kolay olsun diye basit alçı sıkılama makinesi, Şekil 2'deki gibi tekerlekli tasarlanmış ve ilk defa Dinar kireçtaşı ocağında kullanılmıştır. İki adet alçı torbası ve 42 litre su, 89 $\mathrm{mm}$ çapında ve toplam sıkılama boyu 1,5 metre olan 6 adet deliğe şarj edilmiştir. Karıştırma haznesi altında kalan ve bir aracın aküsünden inverter atacıllğyla elektrik alan bir küçük elektrik motoru karıştırmayı başarı ile gerçekleştirmiştir.

Makinenin alt aksamında bulunan çıkış borusu ile karışım deliklere şarj edilmek istenmiştir. Gravite yeterli gücü sağlayamadığından, son birkaç delik şarj edilememiştir. Bu yüzden kalan malzeme karıştırma haznesinden mekanik olarak elle boşaltılmıştır. Dolayısı ile boru içindeki ve makine dibindeki küçük bir miktar karışım işlem bitimine yakın zamanda tamamen donmuştur. Bu çalışmadan, şarjın gravite ile mümkün olmadığı anlaşılmıştır. Karıștırma kovası ile bu sorun aşılmaya çalışılmıştır. Patlatma sonrasında ise Wipfrag Yazılımı ile yığınların parça boyut dağılımı karşılaştırılmıştır.

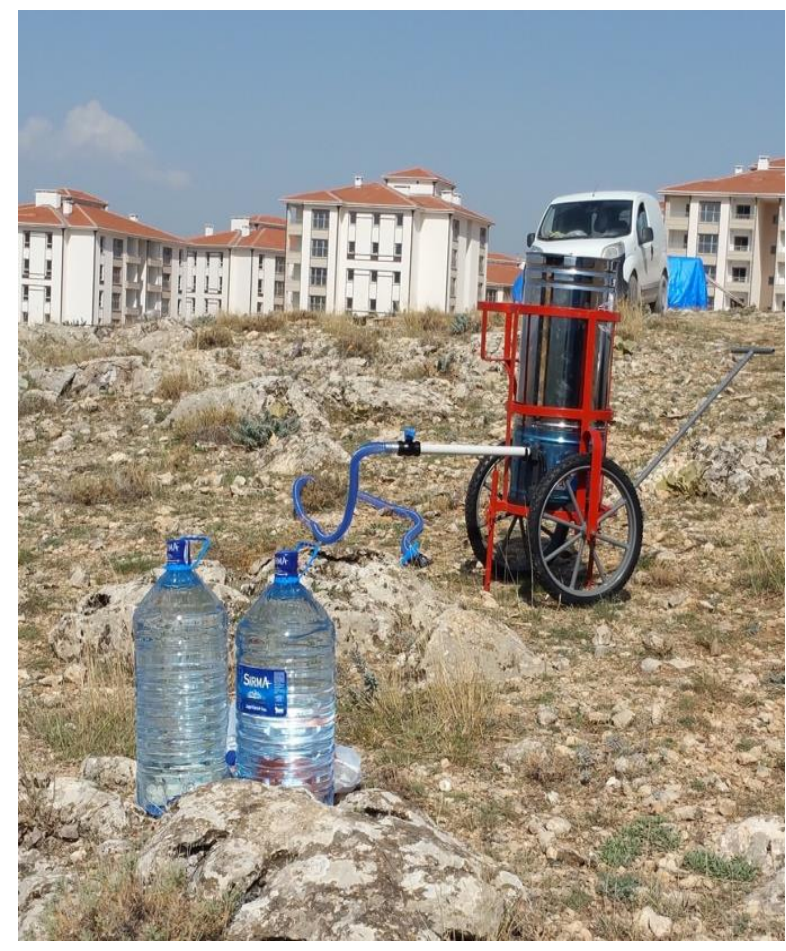

Şekil 2. Basit alçı sıkılama makinesi

Tablo 1. Temel patlatma parametreleri

\begin{tabular}{|c|c|c|c|c|c|c|c|c|}
\hline Atım & $\begin{array}{c}\text { Delik boyu } \\
\text { (m) }\end{array}$ & $\begin{array}{l}\text { Delik çapı } \\
\text { (mm) }\end{array}$ & Sik. (m) & $\begin{array}{l}\text { Anfo ttüket. } \\
\text { ((kg/de) }\end{array}$ & $\begin{array}{l}\text { Dilim kalınl. } \\
(\mathrm{m})\end{array}$ & $\begin{array}{l}\text { Delikler arası } \\
\text { mes.(m) }\end{array}$ & $\begin{array}{l}\text { Özgül şarj } \\
\left(\mathrm{kg} / \mathrm{m}^{3}\right)\end{array}$ & $\begin{array}{c}\text { Spesif. delme } \\
\left(\mathrm{m} / \mathrm{m}^{3}\right)\end{array}$ \\
\hline Dinar taș $\mathrm{t}$ & 16 & 89 & 3 & 65 & 3 & 3 & 0,48 & 0,119 \\
\hline Dinar alçı sıkılama & 16 & 89 & 1,5 & 72,5 & 3,45 & 3,45 & 0,41 & 0,090 \\
\hline
\end{tabular}


Bunun yanında, Bozanönü kireçtaşı ocağında, ucuna karıştırma çırpanı takılı şarjlı matkap ile bu sefer alttan değil de üstten müdahale edilerek karıștırılan solüsyon, aynı şekilde alttan boru ile değil de üstten devirme yöntemiyle deliklere şarj edilmiştir (Şekil 3). Böylece alçının donma süresine kadar tüm işlemlerin gerçekleştirilmesi hedeflenmiştir. Bahçeköy olivin ocağında ise; 2 adet üstü açık ve silindirik metal düzenek, dökme aparatı bulunan kovalar kullanılmıştır (Şekil 4 ve Şekil 5).

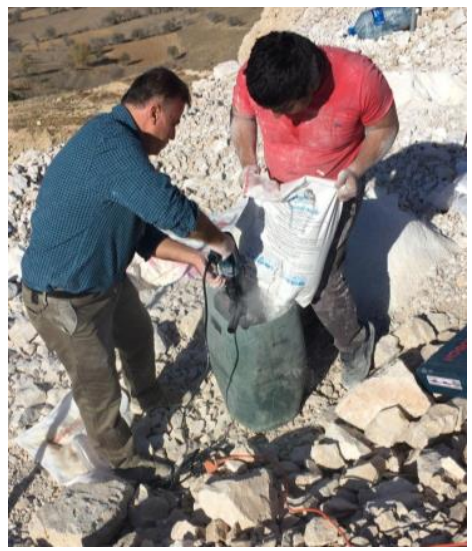

Şekil 3. Bozanönü kireçtaşı ocağı alçı sıkılama uygulaması

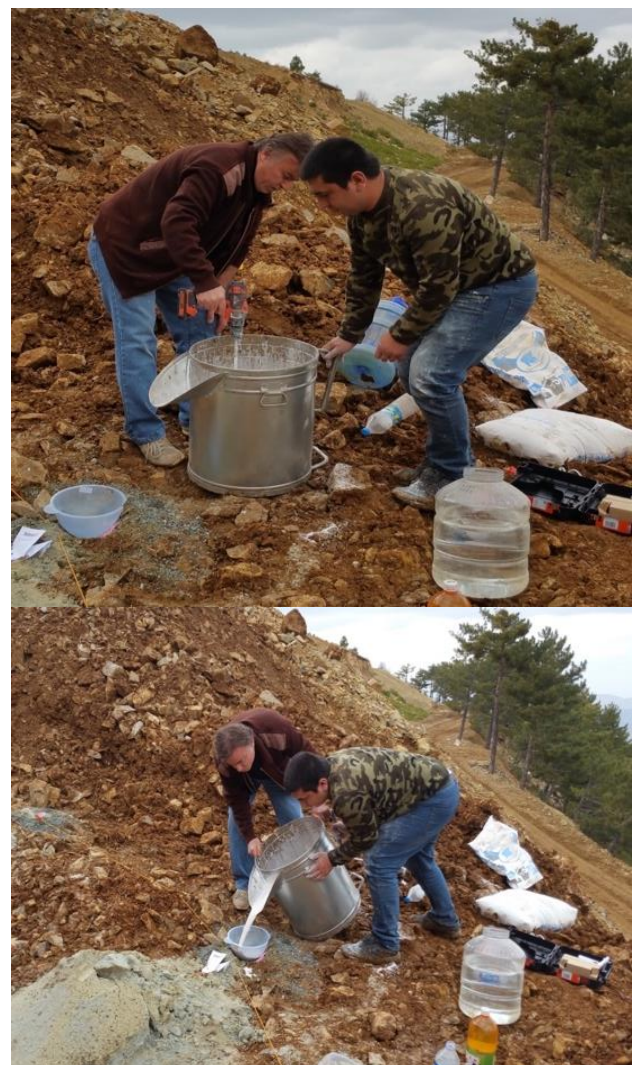

Şekil 4. Birinci tip kova ile delik başında alçı ve su karışımının hazırlanması ve deliğe şarjı

Taşıma kolaylığı açısından iki tarafta kulpu bulunan daha küçük kapasiteli kova kullanılmıştır. Böylece daha başarılı bir şekilde alçı sıkılama uygulanabilmiştir. Alçı çuvalları alt kısımlarından bir miktar yırtıldıktan sonra yavaș yavaș suyun içine karıştırılmıştır. Senkronize olarak da şarjlı çırpanlar yardımı ile karıştırılarak solüsyon hazırlanmıştır. Söz konusu karışım hemen deliklerin başında hazırlanmış olup, hazırlanan solüsyon, derhal deliklere bir huni yardımıyla dökülmüştür. Sonrasında ise sıkılama makinesi ve ekipmanlar bölgeden uzaklaştırılmıştır. $\mathrm{Bu}$ süre, alçının kuruması için yeterli zaman sağlamaktadır.

Daha iyi mekanik özellik taşıyan bir alçı tıkacı oluşturmak için; üzerinde yaklaşık $30 \mathrm{~kg}$ yazan alçı çuvalları tartılmalıdır. Örneğin 30,7 kg'lık çuval için 21 litre değil 21,5 litre su kullanılmalıdır (10 kg alçıya 7 litre su oranına göre).

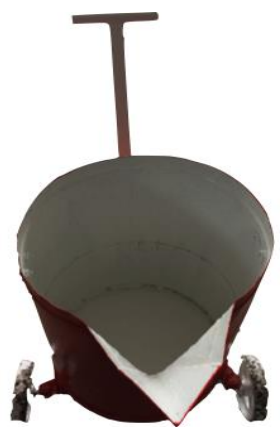

Şekil 5. Bahçeköy’de kullanılan ikinci tip kova

\section{Bulgular}

Basit alçı sıkılama makinesi ile ilk çalışmada, karıştırma başarıyla gerçekleştirilmiş ne var ki, deliğe şarj başarılı olmamıştır. $\mathrm{Bu}$ yüzden alternatif karıștırma ve şarj yöntemleri araştırılmıştır.

Çalıșmalar boyunca, daha önce karşılașılan [5] alçı ve yan kayacın birlikte kopması olayı ile karşılașılmıștır (Şekil 6). Bu, ideal sıkılama anlamına gelmektedir.

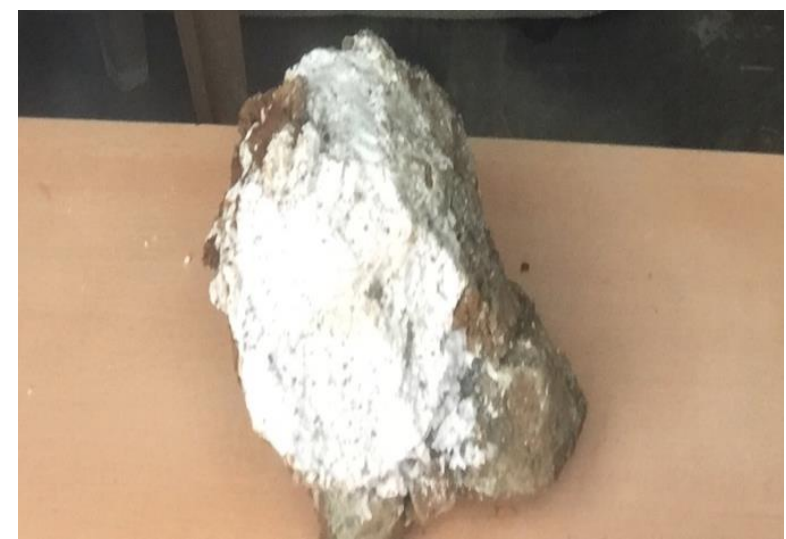

Şekil 6. Atım sonrası olivin kayacı ile birlikte hareket eden alçı - yan kayaç kütlesi

Alçı sıkılamalı atımlar \% 15 civarı fazla dilim kalınlığı ve deliklerarası mesafe uygulanmıştır. Böylece alçı sıkılamada birim delikten daha fazla ürün alınmıștır (yaklaşık \% 30 daha fazla). Aslında alçı sıkılama yönteminin temel avantajı da budur. Yani, aynı delikle, daha fazla ürün (bu çalışmada \%15 dilim kalınlığı ve deliklerarası mesafe artışı ile yaklaşık \%30 fazla patlatılmış kayaç) almaktır. Sıkılama 
boyunun düşmesi ile 1,5 m fazladan yapılan Anfo şarjı delik başına 7,5 kg'lık fazla şarj demektir. Bu fazlalık, yaklaşık \%5 delme- patlatma maliyetine karşı gelmektedir.

Dinar kireçtaşı ocağına ait maliyet analizi Tablo 2'de verilmiştir. Maliyet konusunda, ideal olan, her iki sıkılama yönteminde 55'er delik patlatılarak karşılaştırmaktır. Ne var ki, alçı sıkılamayı 55 deliğe uygulamak zordur. Bu yüzden alçı sıkılamalı atımda 6 delik patlatılmıştır. Bu yüzden 55 deliğe uyarlanmış bir maliyet hesaplanmıștır (örneğin ateşleyici elektrikli kapsül maliyeti 55 deliğin 6 deliğe oranıyla verilmiştir). Bir başka deyişle, 55 deliklik bir alçı sıkılma yapılsaydı, birim ürün için Tablo 2'de belirtilen maliyet oluşacaktı.

Tablo 2. Dinar kireçtașı ocağına ait maliyet analizi

\begin{tabular}{|c|c|c|}
\hline \multirow[b]{2}{*}{ Malzemeler } & \multicolumn{2}{|c|}{ Maliyet (TL) } \\
\hline & $\begin{array}{l}\text { Taş Tozu } \\
\text { (55 delik) }\end{array}$ & $\begin{array}{c}\text { Alçılı } \\
\text { (6 delik) }\end{array}$ \\
\hline Anfo & $\begin{array}{c}16463,65 \\
(65 \times 55 \times 4,61)\end{array}$ & $\begin{array}{c}2003,27 \\
(72,5 \times 6 \times 4,61)\end{array}$ \\
\hline $\begin{array}{l}\text { Nonel (Yüzey + } \\
\text { delik içi) }\end{array}$ & $\begin{array}{c}2505,11 \\
(45,55 \times 55)\end{array}$ & $\begin{array}{c}273,29 \\
(45,55 \times 6)\end{array}$ \\
\hline Adi kapsül & 12,17 & 1,33 \\
\hline Dinamit & $\begin{array}{c}415,02 \\
(7,55 \times 55)\end{array}$ & $\begin{array}{c}45,28 \\
(7,55 \times 6)\end{array}$ \\
\hline $\begin{array}{l}\text { Akaryakıt } \\
\text { Maliyeti }\end{array}$ & 3669,38 & 400,3 \\
\hline $\begin{array}{l}\text { Delici Makine } \\
\text { Kirası }\end{array}$ & 11000 & 1200 \\
\hline Alçl, su ve işcilik & - & 100 \\
\hline Zil Teli & 157,79 & 17,21 \\
\hline $\begin{array}{l}\text { Ruhsat Takip } \\
\text { Masrafları }\end{array}$ & 180,33 & 19,67 \\
\hline Hizmet Bedeli & 90,16 & 9,84 \\
\hline Ulaşım Giderleri & 901,64 & 98,36 \\
\hline Bit Ucu & 2714,93 & 296,17 \\
\hline Arıza Giderleri & 180,33 & 19,67 \\
\hline $\begin{array}{l}\text { Patlayıcı Nakliye } \\
\text { Giderleri }\end{array}$ & 180,33 & 19,67 \\
\hline $\begin{array}{l}\text { Delici Rock } \\
\text { nakliye Giderleri }\end{array}$ & 450,82 & 49,18 \\
\hline Toplam Maliyet & 38921,66 & 4553,24 \\
\hline & \multicolumn{2}{|c|}{$\mathrm{m}^{3}$} \\
\hline Yerinde Hacmi & $\begin{array}{c}7425 \\
(15 \times 3 \times 3 \times 55)\end{array}$ & $\begin{array}{c}1071 \\
(15 \times 3,45 \times 3,45 \times 6)\end{array}$ \\
\hline Birim Malivet & \multicolumn{2}{|c|}{$\mathrm{TL} / \mathrm{m}^{3}$} \\
\hline Birım ivanye๘ & 5,24 & 4,25 \\
\hline
\end{tabular}

Dinar kireçtaşı ocağında yapılan, sırasıyla alçı sıkılamalı ve taş tozu sıkılamalı atımlara ait gürültü ve titreşim ölçümü değerleri $\mathrm{Ek} A$ ve $\mathrm{Ek} \mathrm{B}^{\prime} \mathrm{de}$ verilmiştir. Alçı sıkılamalı atımda her delik ayrı gecikme ile patlatılırken, taş tozu sıkılamada 1,2 veya 3 delik birim zamanda patlatılmıștır. Buna rağmen titreşim değerleri yakın seviyededir. Titreşim kaydı her iki atıma eşit olan bir noktadan ölçülmüştür.

Bilindiği üzere, alçı sıkılamada, sıkılama boyu küçülmüş ve patlayıcı şarj boyu dolayısıyla da miktarı artmıştır. $\mathrm{Bu}$, birim zamanda patlayan patlayıcı miktarının artışı anlamına gelir. Önceki çalışmalarda
$[3,6,10,11]$, artan patlayıcı ve oluşan titreşim bağıntısı;

$$
S D=D / W^{(1 / 2)}
$$

Formülüne [12] göre; fazla patlayıcının neden olması beklenen titreşim artışından kat kat fazla titreșim artışı ölçülmüştür. Bu da, alçı sıkılamanın daha iyi enerji kullandığını gösterir.

Atımların parça boyut analizi Wipfrag yazılımı ile yapılmıştır (Şekil 7 ve 8). Dinar atımları kümülatif elek üstü oranları Tablo 3'de verilmiştir. Bu tablodan, alçı sıkılamanın daha iyi parçalanma sağladığı görülmektedir. Örneğin $215 \mathrm{~mm}$ boyut için kümülatif elek üstü \%47'den \%70' e çıkmıştır. D50 boyutu taş tozu sıkılama yönteminde $426 \mathrm{~mm}$ alçı sıkılama yönteminde ise da 206 mm'dir.

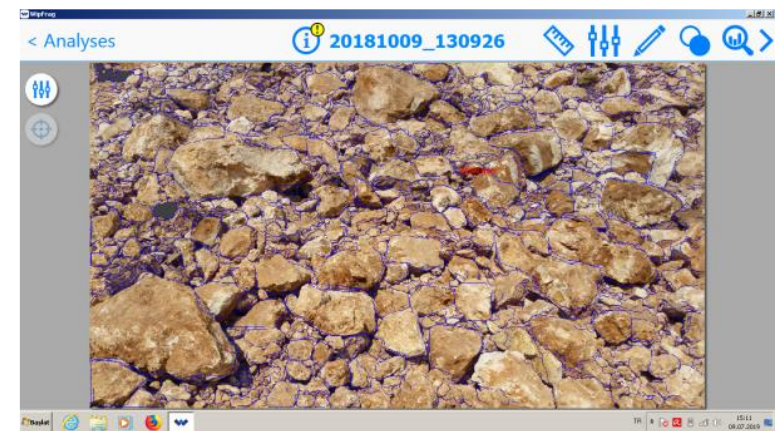

Şekil 7. Dinar ocağı taş tozu sıkılamalı atımın Wipfrag ile parça boyut analizi

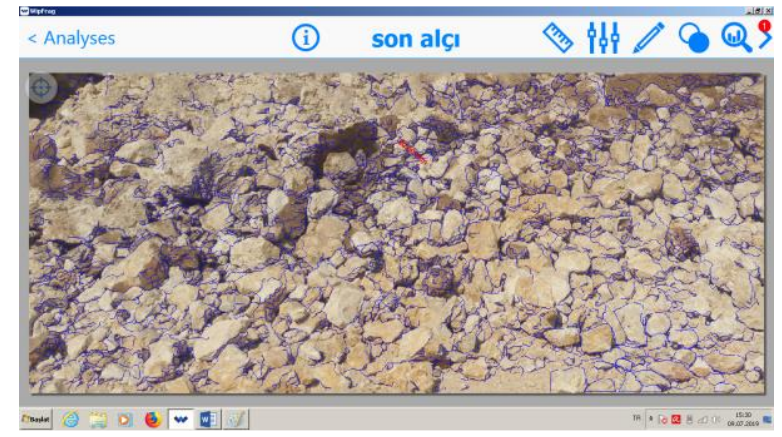

Şekil 8. Dinar ocağı alçı sıkılamalı atımın Wipfrag ile parça boyut analizi

Tablo 3. Dinar atımları kümülatif elek üstü oranları

\begin{tabular}{ccc}
\hline $\begin{array}{c}\text { Tane Boyutu } \\
(\mathrm{mm})\end{array}$ & $\begin{array}{c}\text { Taş tozu } \\
\text { sıkımalı(\%) }\end{array}$ & $\begin{array}{c}\text { Alçı } \\
\text { Sıkılamalı(\%) }\end{array}$ \\
\hline 1000 & 14,4 & 0 \\
681 & 34,5 & 0 \\
464 & 47 & 6,8 \\
316 & 58,8 & 21,3 \\
215 & 70,2 & 47,4 \\
147 & 81,6 & 67,8 \\
100 & 90,6 & 80,1 \\
68,1 & 96,2 & 88,1 \\
46,4 & 98,6 & 93,2 \\
31,6 & 99,5 & 96,9 \\
21,5 & 99,8 & 98,8 \\
14,7 & 99,9 & 99,5 \\
10 & 99,9 & 99,8 \\
6,81 & 100 & 99,9 \\
\hline
\end{tabular}


$\mathrm{Bu}$ çalışmanın temel amacı yeni bir sıkılama yönteminin arazide uygulama zorluğunun aşılması olup, alçı sıkılama yönteminin kârlılığı çok sayıda çalışmada $[3,5,6]$ net bir şekilde ortaya konmuştur. Benzer şekilde, birim zamandaki patlatılan patlayıcıya göre artan titreşim vb. ölçüm ve hesaplamalar açıkça ortaya konulmuştur [3,6,10,11].

\section{Tartışma ve Sonuç}

Alçı sıkılamanın patlatma randımanını yüksek seviyelerde arttırdı̆̆ı önceki çalışmalardan da bilinmektedir. Çok sayıda çalışmada $[3,4,5,6,10,13]$ alçı sıkılama ile başarılı sonuçlar alınmıştır. Ayrıca, numerik simülasyon ile de bu sonuç teyit edilmiştir [14].

$\mathrm{Bu}$ çalışmada ise alçı sıkılamanın makineyle yapılması ile uygulamadaki dezavantaj olan zaman ve zahmet sorunu için fayda sağlanmıştır. Sıkılamanın alçıyla yapılması sıkılama boyunu azalttığından patlayıcı şarjı bir miktar artmıştır. Böylece, delik başına Anfo miktarı artarken, patternin değişmesiyle birim kayaca düşen Anfo miktarı azalmış ve buna bağlı olarak patlatma başarısı da artmıştır. Ayrıca alçının kurumasıyla beraber yan kayaca kaynayan alçı Şekil 6'daki gibi kayaç ile birlikte hareket etmiștir. Bu da ideal sıkılama anlamına gelir. Tüm bu işlemlerde, bir takım basit ekipmanlarla daha hızlı, başarılı ve kolay bir şekilde alçı sıkılamanın uygulanabileceği anlaşılmıştır.

Bunların yanında taş tozu sıkılamanın yapıldığı patlatmalar ile karşılaştırmalar yapılmıştır. Buna göre alçı sıkılama ile daha iyi parçalanma daha ucuza mâl edilmiștir.

Özgül şarj ve spesifik delme oranı alçı sıkılamalı atım için, taş tozu sıkılamalı patlatmaya göre düşüş göstermiştir. Özgül şarj $0,48 \mathrm{~kg} / \mathrm{m}^{3^{\prime}}$ den $0,41 \mathrm{~kg} / \mathrm{m}^{3^{\prime}} \mathrm{e}$, spesifik delme de $0,119 \mathrm{~m} / \mathrm{m}^{3^{\prime}}$ dan $0,090 \mathrm{~m} / \mathrm{m}^{3^{\prime}} \mathrm{e}$ düşmüștür.

Fakat alçı sıkılama ișlemi kârlı ve bașarılı olmasına rağmen kullanımının yaygınlaşmaması yöntemin tanıtılması ve benimsenmesi ile ilgili olduğu düşünülmektedir. Teknik ve ekonomik olarak açıkça kârlılığı bilinse de yeni bir yöntem için ergonomi, psikolojik ve sosyal etkiler de önemlidir [7].

Cazibeyle (yer çekimi) şarjın mümkün olmayacağı ve başka bir yolla şarj zorunluluğu arazi çalışmalarından anlaşılmıştır. Uygun kova ve huni yardımıyla bu sorun aşılabilmiştir.

Gelecek çalışmalarda daha profesyonel makinelerle alçının karıștırılarak deliğe şarj edilmesinin, yöntemin yaygınlaşmasına katkı sağlayacağ değerlendiril-mektedir.

\section{Teşekkür}

Yazarlar, bu çalışmayı FYL-2018-5860 no'lu proje ile destekleyen SDÜ-BAP Koordinasyon Birimine ve yapıcı eleştirileri ile makalenin düzenlenmesine ve geliştirilmesine katkı sağlayan hakemlere teşekkür eder.

\section{Etik Beyanı}

Bu çalışmada, "Yükseköğretim Kurumları Bilimsel Araștırma ve Yayın Etiği Yönergesi" kapsamında uyulması gerekli tüm kurallara uyulduğunu, bahsi geçen yönergenin "Bilimsel Araştırma ve Yayın Etiğine Aykırı Eylemler" başlığı altında belirtilen eylemlerden hiçbirinin gerçekleştirilmediğini taahhüt ederiz.

\section{Kaynakça}

[1] Snelling W, Hall C. 1912. The Effects of Stemming on the Efficiency of Explosives. USBM-TP, 17, 1-20.

[2] Cevizci, H. 2010. Açık Ocak Patlatmalarında Sıkılama Parametresinin Patlatma Verimliliğine Etkisi. Süleyman Demirel Üniversitesi, Fen Bilimleri Enstitüsü, Yüksek Lisans Tezi, 98s, Isparta.

[3] Cevizci, H. 2012. A Newly Developed Plaster Stemming Method for Blasting. The J. Of the South African Instutute of Mining And Metallurgy, December, 1071-1078.

[4] Cevizci, H. Özkahraman, H.T. 2012. The effect of blast hole stemming length to rockpile fragmentation at limestone quarries. International Journal of Rock Mechanics and Mining Sciences, 53, 32-35.

[5] Cevizci, H. 2013. A New Stemming Application for Blasting: A Case Study, Rem: Rew. Esc. Minas, Dec., 513-519.

[6] Cevizci, H. 2014. Fragmentation, Cost and Environmental Effects of Plaster Stemming Method for Blasting at a Blast Quarry, Archives of Mining Science, 59(3), 837-848.

[7] Rehman, A.U., Emad, M.Z., Khan, M.U. 2020. Role of Ergonomics in the Selection of Stemming Plugs for Surface Mining Operations, Archives of Mining Science, 65(1), 59-70.

[8] Cevizci, H., Sakçalı, A., Akçakoca,H. 2013 Alçı Sıkılama Yöntemi ve Çevresel Etkileri. VII. Delme - Patlatma Sempozyumu, 7-8 Kasım, Eskişehir, 191-198.

[9] Sürücüoğlu, H. 2019. Alçı Sıkılama Yöntemi için Arazide Uygulama Kolaylı̆̆ının Araştırılması. Süleyman Demirel Üniversitesi, Fen Bilimleri Enstitüsü, Yüksek Lisans Tezi, 75s, Isparta. 
[10] Cevizci, H. 2017. The Effect of Plaster Stemming for Large Hole Diameter Stripping Blasting: A Case Study. Proceedings of 25th International Mining Congress and Exhibition of Turkey, Chamber of Mining Engineers of Turkey, 11-14 April, Antalya, 333-339.

[11] Cevizci, H. 2015. The environmental and ecological effects of plaster stemming method for blasting: A case study. Ekoloji, 24(95), 1722.

[12] Devine J., Beck R., Meyer A, Duvall W. 1966. Effect of charge weight on vibration levels from quarry blasting. USBM, Washington, 42s.
[13] Pina, M. S. 2017. Análise da Eficiência do Desmonte de Explosivos com uso de Tampão não Convencional Rígido de Gesso, Universidade Federal de Fernembuco, Dissertaçoes de Mestrado, Engenharia Mineral123p, Pernambuco, Recife, Brasil.

[14] Cevizci, H. 2019 Comparison of the Efficiency of Plaster Stemming and Drill Cuttings Stemming by Numerical Simulation. The Journal of the South African Institute of Mining and Metallurgy, May, 160-165. 
Ekler

Ek A. Dinar ocağı alçı sııılamalı atımın titreșim ve hava şoku verileri

\section{Event Report}

\section{Instantel}

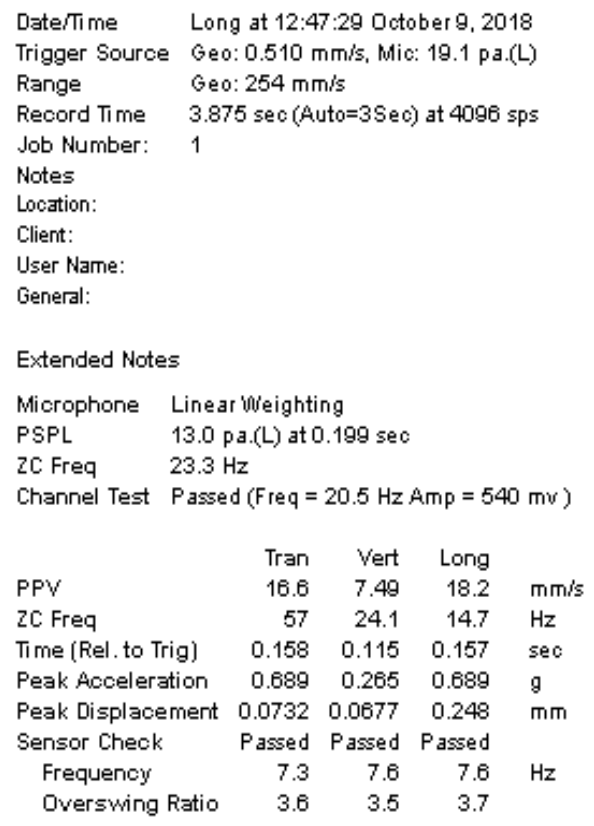

Peak Vector Sum $24.0 \mathrm{~mm} / \mathrm{s}$ at $0.158 \mathrm{sec}$

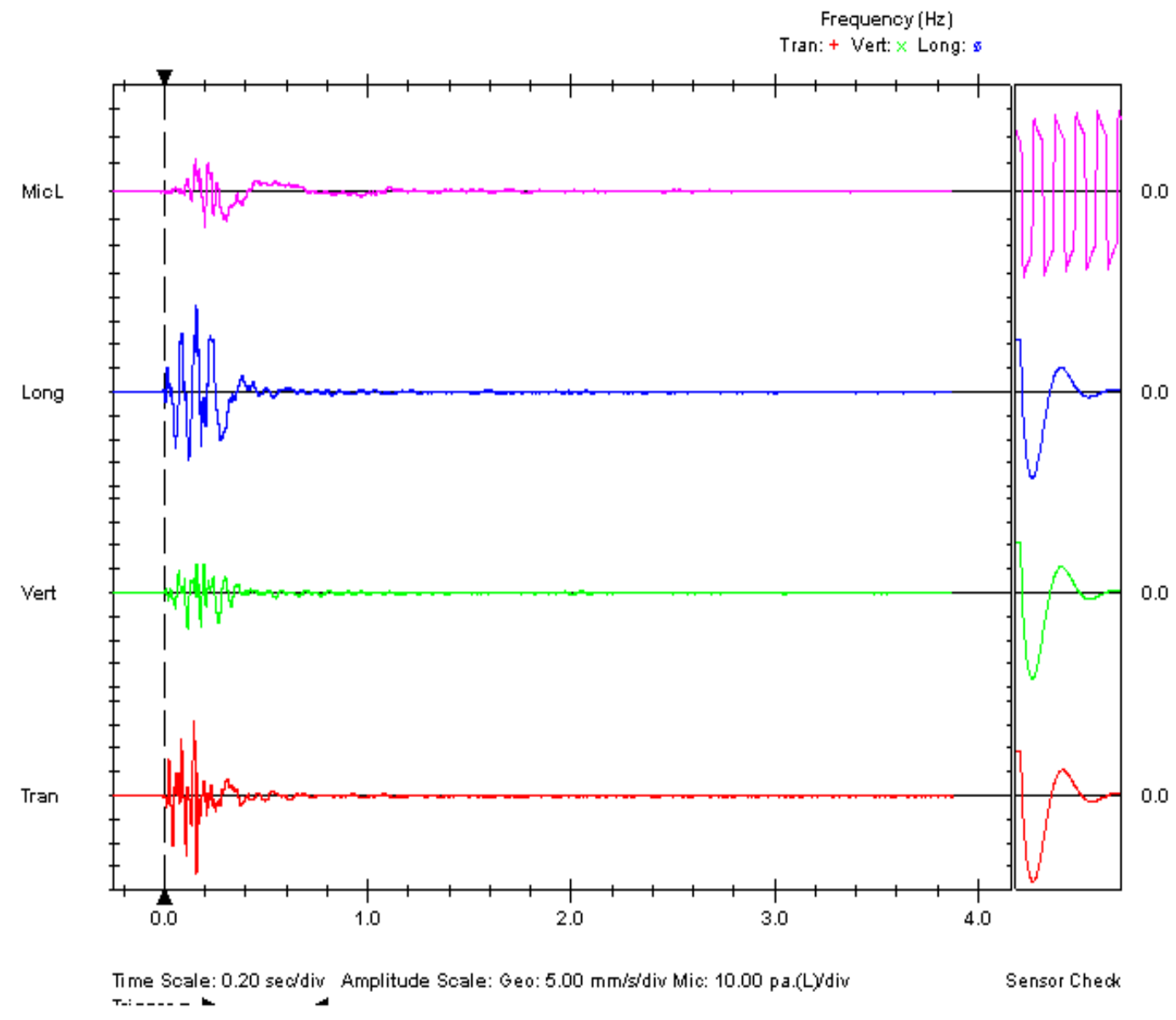

Printad: Oxtobar $9,2012\left(V_{10} 10.60-10.60\right)$
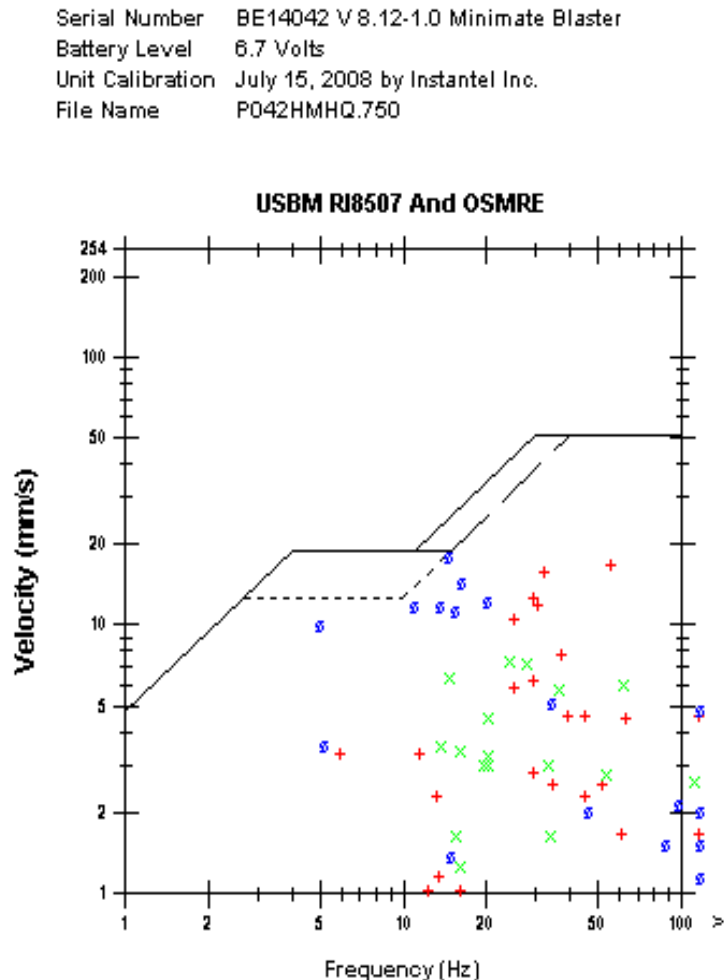

Tran: + Vert: $\times$ Long: 
Ek B. Dinar ocağı taş tozu sıkılamalı atımın titreșim ve hava şoku verileri

\section{E Instantel}

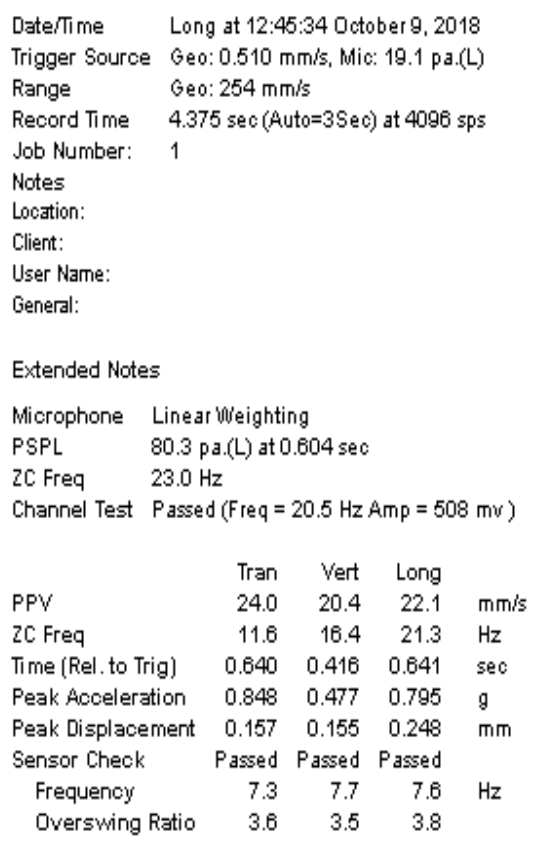

Peak Vector Sum $32.1 \mathrm{~mm} / \mathrm{s}$ at $0.640 \mathrm{sec}$
Event Report $\begin{array}{ll}\text { Serial Number } & \text { BE14042 V 8.12-1.0 Minimate Blaster } \\ \text { Battery Level } & 6.8 \text { Volts } \\ \text { Unit Calibration } & \text { July 15, } 2008 \text { by Instantel Inc. } \\ \text { File Name } & \text { P042HMHO.3YO }\end{array}$

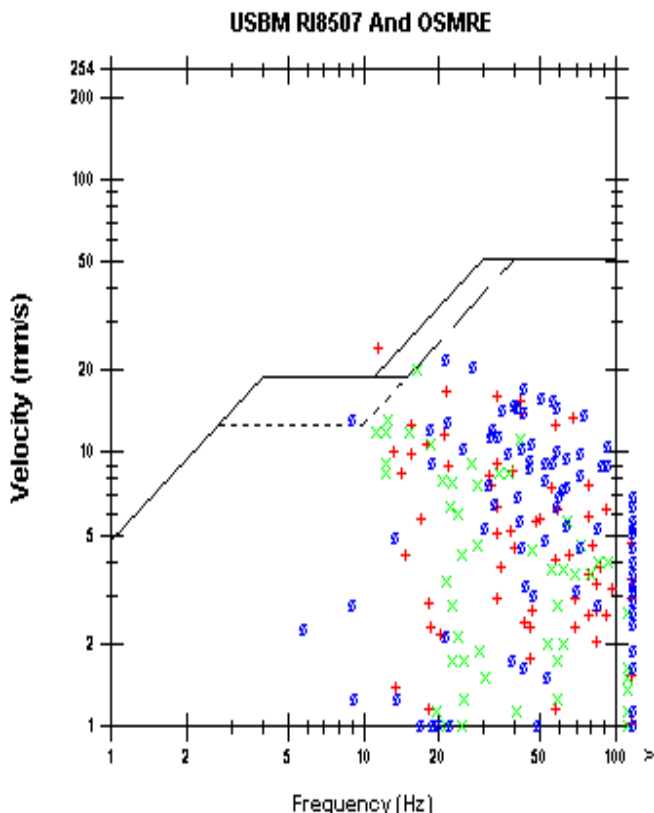

Tran: + Vent:

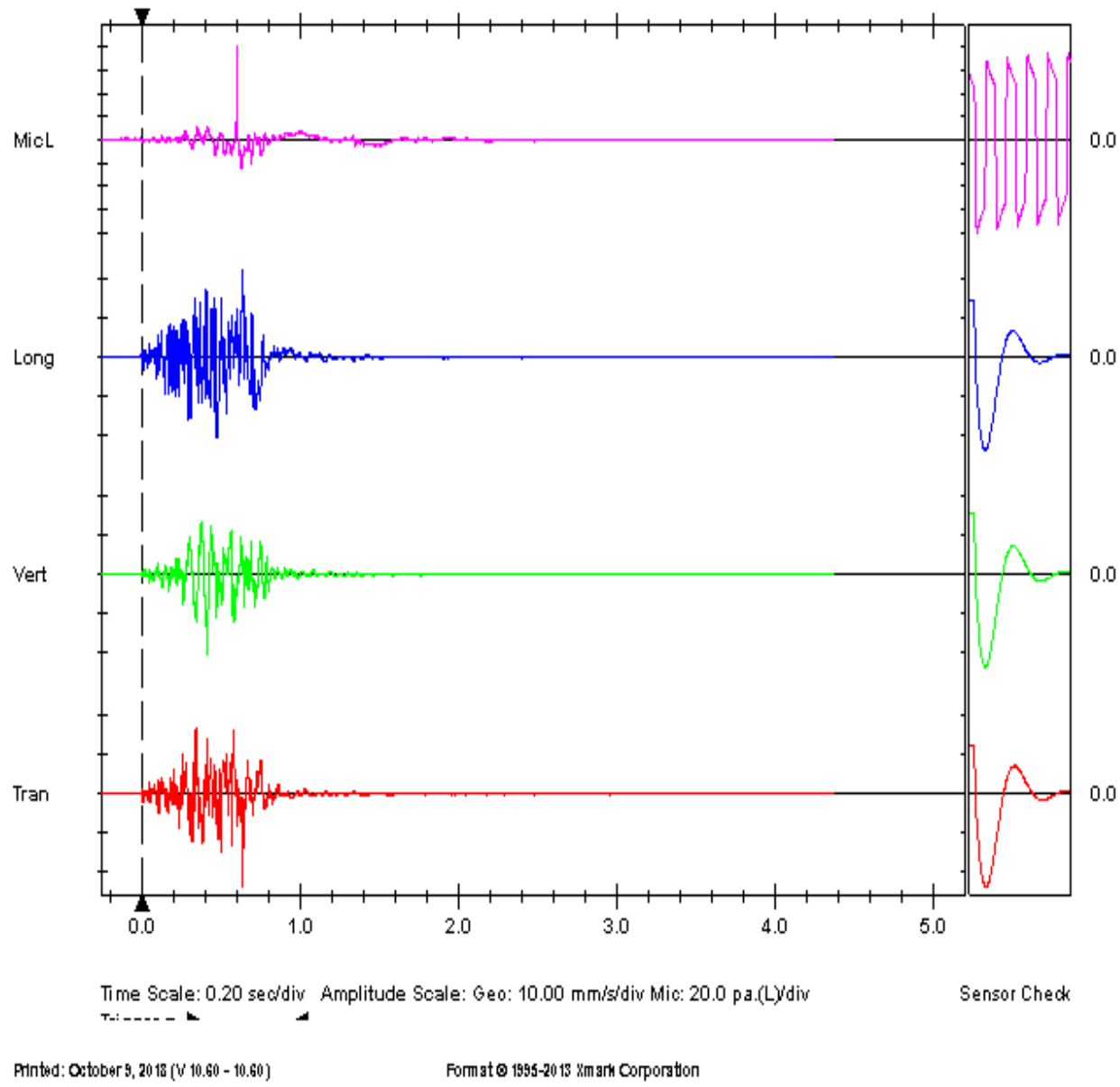

